\title{
Effects of vitamin D supplementation on insulin resistance and dyslipidemia in overweight and obese premenopausal women
}

\author{
Narin Nasiroglu Imga ${ }^{1}$, Alper Cagri Karci ${ }^{1}$, Dilek Oztas ${ }^{2}$, Dilek Berker ${ }^{1}$, Serdar Guler ${ }^{1}$
}

\begin{abstract}
${ }^{1}$ Department of Endocrinology, Ankara Numune Education and Research Hospital, Saglik Bilimleri University, Ankara, Turkey

2Department of Public Health, Medical School, Yildirim Beyazit University, Ankara, Turkey
\end{abstract}

Submitted: 22 March 2018

Accepted: 25 April 2018

Arch Med Sci 2019; 15 (3): 598-606

DOI: https://doi.org/10.5114/aoms.2018.75864

Copyright $\odot 2018$ Termedia \& Banach

\section{Abstract}

Introduction: Vitamin D deficiency is a common problem, and it is related to increased risk of obesity, metabolic syndrome, atherosclerosis, and cardiovascular disease. Vitamin D has a beneficial effect on dyslipidemia and insulin secretion. We aimed to investigate the impact of vitamin $D_{3}$ supplementation on anthropometric and laboratory parameters in overweight and obese premenopausal women.

Material and methods: Seventy-two overweight and 50 obese vitamin-D-deficient premenopausal women (mean age: $43.1 \pm 10.4$ years) were included in the study. Baseline mean 25-hydroxyvitamin D [25(OH)D] level was 6.1 $(\min .-\max .=2.9-15.8) \mathrm{ng} / \mathrm{ml}$ in overweight and was $5.6(\min .-\max .=3.0-$ 22.0) $\mathrm{ng} / \mathrm{ml}$ in obese subjects. At baseline and at the sixth month of supplementation, serum 25(OH)D, intact parathormone (iPTH), calcium, phosphorus, homeostasis model assessment of insulin resistance (HOMA-IR), and lipid profiles were assessed.

Results: Following vitamin $D_{3}$ supplementation in overweight and obese subjects, serum 25(OH)D increased from 6.1 to $34.7 \mathrm{ng} / \mathrm{ml}$ and 5.6 to $34.7 \mathrm{ng} /$ $\mathrm{ml}$, respectively $(p<0.001)$. At the sixth month of supplementation in both overweight and obese subjects, a significant reduction was detected in $\mathrm{HO}$ MA-IR $(p<0.001)$, low-density lipoprotein cholesterol (LDL-C) $(p=0.046$, $p=0.044$; respectively) and iPTH levels ( $p \leq 0.001, p<0.001$; respectively). A negative adjusted correlation was found between changes in $25(\mathrm{OH}) \mathrm{D}$ and HOMA-IR ( $r=-0.581, p<0.001 ; r=-0.389, p=0.005$; respectively). A $1 \mathrm{ng} /$ $\mathrm{ml}$ increase in serum $25(\mathrm{OH}) \mathrm{D}$ level led to a 0.30 -fold reduction in HOMA-IR level $(p=0.002)$.

Conclusions: Our results support the effect of vitamin $D_{3}$ supplementation in HOMA-IR and LDL-C improvement in both obese and overweight subjects. Further studies focused on low serum 25(OH)D levels with insulin resistance and dyslipidemia are needed.

Key words: obesity, insulin resistance, calcitriol, dyslipidemias.

\section{Introduction}

Vitamin $D$ is a unique hormone produced in the skin through exposure to ultraviolet (UV) irradiation of 7-dehydrocholesterol. Low vitamin D levels are characteristically seen as a result of the reduced cutaneous

\author{
Corresponding author: \\ Dr. Narin Nasiroglu Imga \\ Department \\ of Endocrinology \\ Ankara Numune \\ Education and \\ Research Hospital \\ 06100 Ankara, Turkey \\ E-mail: xnarinx@yahoo.com
}


synthesis of 25-hydroxyvitamin D $(25(\mathrm{OH}) \mathrm{D})$ due to a lack of UV light [1]. The best-known effect of vitamin D status is on musculoskeletal health, but it also influences the cardiovascular system and all-cause mortality [2, 3].

Vitamin D deficiency and obesity are considered important public health problems. Some studies have demonstrated an inverse relationship between 25(OH)D levels and metabolic syndrome, obesity and insulin resistance in patients [4-8], while others showed no beneficial effect [9-13]. However, in these studies, various differences were observed in study design, population, duration, type and initial vitamin D levels. Therefore, further clinical studies are needed to resolve this issue.

Vitamin D supplementation in vitamin D deficient prediabetic individuals is related to lower progression to diabetes mellitus (DM) [14]. Recent studies have reported a relationship between vitamin D deficiency and the pathogenesis of dyslipidemia [15]. It is considered that vitamin D has direct effects on lipid levels by maintaining adequate levels of apolipoprotein Al, a major component of high-density lipoprotein cholesterol (HDL-C). Also, vitamin D could indirectly influence lipid metabolism through parathormone $(\mathrm{PTH})$ or calcium balance $[16,17]$.

In this study, we aimed to investigate the impact of vitamin $D_{3}$ supplementation on insulin resistance and dyslipidemia as prognostic risk factors for subclinical atherosclerosis in healthy overweight and obese premenopausal women.

\section{Material and methods}

\section{Subjects}

The medical records of patients admitted to Ankara Numune Education and Research Hospital, Endocrinology and Metabolism Department, between September 2015 and May 2016, were retrospectively evaluated. Records from 1,775 potential female subjects who received vitamin $D_{3}$ supplementation were searched. 1,347 potential subjects were excluded from the study because of the following criteria: history of menopause, body mass index $(\mathrm{BMI})<25 \mathrm{~kg} / \mathrm{m}^{2}$, atherosclerotic disease, stroke, chronic inflammatory disease, hepatic and renal impairment, DM, hypertension, dyslipidemia, current smoking, malignancy, malabsorption, using any drugs that affect $25(\mathrm{OH}) \mathrm{D}$, antihypertensive drugs, statins and oral contraceptives or being involved in any diet or exercise program. A further 303 women were excluded because they did not meet the criterion of $25(\mathrm{OH}) \mathrm{D}$ level $<30 \mathrm{ng} / \mathrm{ml}$ after supplementation or because some laboratory data were missing. Consequently, 122 overweight $(n=72)$ and obese $(n=50)$ premenopausal women followed for vitamin $\mathrm{D}$ deficiency who reached the target level of 25(OH)D ( $\geq 30 \mathrm{ng} / \mathrm{ml}$ ) after supplementation were selected (Figure 1$)$.

A deficiency of vitamin $D$ is defined as serum concentration of 25(OH)D below $20 \mathrm{ng} / \mathrm{ml}$. Following supplementation, the cut-off level of adequate 25(OH)D was accepted above $30 \mathrm{ng} / \mathrm{ml}$. Vitamin D supplementation was administered with 100,000 IU/ week as a loading dose for 8 weeks following a maintenance dose of 3,000 IU/day according to the 2011 Guidelines of the Endocrine Society recommendations for obese and overweight subjects [18].

All parameters were evaluated at baseline and the sixth month of vitamin D supplementation for each subject. Physical examination measurements including height, weight, waist and hip circumference, and blood pressure were recorded. The BMI was calculated as weight $(\mathrm{kg}) /$ height $^{2}\left(\mathrm{~m}^{2}\right)$. Subjects were divided according to $\mathrm{BMI}$ as overweight (BMI: $\left.25-29.9 \mathrm{~kg} / \mathrm{m}^{2}\right)$ and obese $\left(\mathrm{BMI} \geq 30 \mathrm{~kg} / \mathrm{m}^{2}\right)$ groups [19]. The mean values of the three measurements of waist and hip circumferences and waist to hip ratio (WHR) were recorded. The local ethics committee of Ankara Numune Education and Research Hospital approved the study in accordance with the Declaration of Helsinki 2013.

\section{Laboratory analyses}

Serum-corrected calcium, phosphorus, 25(OH)D, intact parathormone (iPTH), fasting blood glucose (FBG), insulin and lipid profile including total cholesterol (TC, mg/dl), triglyceride (TG, mg/dl), $\mathrm{HDL}-\mathrm{C}(\mathrm{mg} / \mathrm{dl})$, and low-density lipoprotein cholesterol (LDL-C, mg/dl) levels were measured. Serum $25(\mathrm{OH}) \mathrm{D}$ concentration was measured using an electroluminescence method on the Cobas E-411 analyzer (Roche Diagnostics $\mathrm{GmbH}$, Mannheim, Germany). The intraassay and interassay coefficients of variation (CV) were $3.2 \%$ and $7.8 \%$, respec-

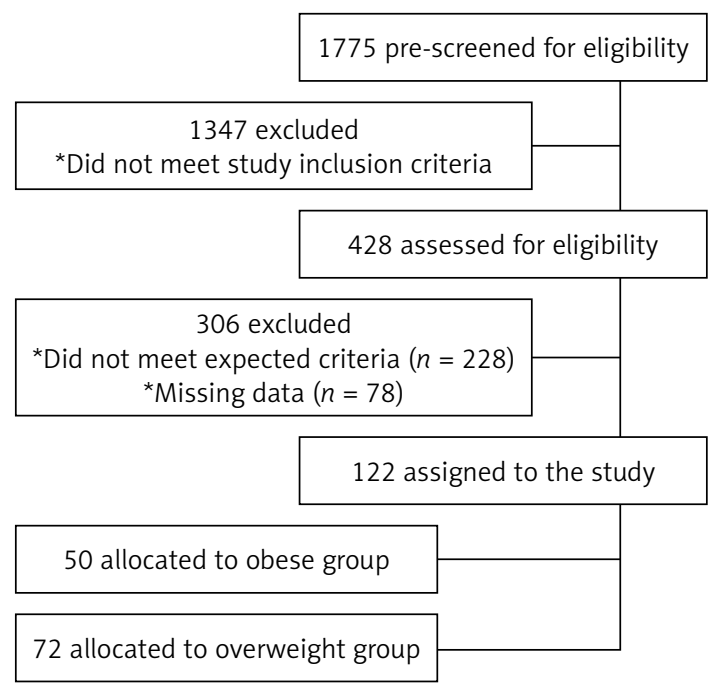

Figure 1. Flow chart of the number of patients identified and included into the study 
tively. The minimum detection limit of the $25(\mathrm{OH}) \mathrm{D}$ kit was $3 \mathrm{ng} / \mathrm{ml}$ and the coefficient of variation was $<10 \%$. Serum iPTH (normal range: $12-88 \mathrm{pg} /$ $\mathrm{ml}$ ) and insulin (normal range: 1.9-23 $\mu \mathrm{lU} / \mathrm{ml}$ ) levels were determined by chemiluminescent immunoassay (AU5800 autoanalyzer, Beckman Coulter Inc., Brea, CA, USA). Serum glucose (normal range: $70-100 \mathrm{mg} / \mathrm{dl}$ ), TG (normal range: 10-200 mg/dl), TC (normal range: $20-200 \mathrm{mg} / \mathrm{dl}$ ), and HDL-C (normal range: 40-60 mg/dl) concentrations were analyzed using the enzymatic method (AU5800 autoanalyzer, Beckman Coulter Inc., Brea, CA, USA). Serum albumin, calcium (normal range: $8.5-10.5 \mathrm{mg} / \mathrm{dl}$ ), and phosphorus (normal range: $2.5-4.5 \mathrm{mg} / \mathrm{dl}$ ) levels were measured by the photometric method (AU5800 autoanalyzer, Beckman Coulter Inc., Brea, CA, USA). Serum LDL-C concentration was calculated using the Friedewald formula [20]. Serum total calcium was corrected for serum albumin with the formula: [(4-albumin $) \times 0.8]$ total serum calcium. All calcium levels were corrected, and the term 'calcium' was used instead of 'corrected calcium'. The homeostasis model assessment of insulin resistance (HOMA-IR) was calculated by the formula HOMA-IR $=(F B G \times$ insulin $) / 405$ [21]. In all study populations, all test parameters were recorded at baseline and the sixth month of supplementation.

\section{Statistical analysis}

Statistical analysis was performed using the Statistical Package for Social Sciences for Windows 20 (IBM SPSS Inc., Chicago, IL) program. The Kolmogorov-Smirnov test assessed the normal distribution of the data. Descriptive statistics are presented as the mean \pm standard deviation for normal distribution, and median (min.-max.) for non-normal distribution. Categorical variables were expressed as number and percentage. Normally distributed parameters were evaluated by the $t$-test, while non-normally distributed parameters were investigated by the Mann-Whitney $U$ test. In the overweight and obese subjects, changes in anthropometric and laboratory findings after vitamin D supplementation were evaluated by the repeated measures ANOVA test. The data of parameters at baseline and after 6 months of supplementation were evaluated by the paired $t$-test. Analysis of the percent relative change in all parameters between groups to demonstrate the effect of treatment was performed by ANOVA. The percent relative change was computed for each parameter with the following formula: (sixthmonth measurement - baseline measurement)/ baseline measurement $\times 100$. The magnitude of absolute change from baseline to after vitamin $D$ supplementation values was indicated by $\Delta$. To establish the relationships between changes in parameters following vitamin D supplementation, the correlations of change in HOMA-IR level with changes in anthropometric and laboratory findings were analyzed by Spearman correlation analysis. The repeated measures design with generalized linear mixed models was used to detect $\Delta 25(\mathrm{OH}) \mathrm{D}$ levels for predicting $\triangle \mathrm{HOMA}$-IR levels. A $p$-value of $p \leq 0.05$ was considered statistically significant.

\section{Results}

Baseline demographic, anthropometric and laboratory characteristics of the groups are shown in Table I. The study population of 122 Caucasian women consisted of 72 (59.0\%) overweight and $50(41.0 \%)$ obese vitamin-D-deficient premenopausal subjects (Table I). Baseline mean 25-hydroxyvitamin D $(25(\mathrm{OH}) \mathrm{D})$ level was 6.1 (min.$\max .=2.9-15.8) \mathrm{ng} / \mathrm{ml}$ in overweight and was 5.6 (min.-max. $=3.0-22.0) \mathrm{ng} / \mathrm{ml}$ in obese subjects. Of all subjects, the mean age was $43.1 \pm 10.4$ years; the mean BMI was $30.8 \pm 4.6 \mathrm{~kg} / \mathrm{m}^{2}$. Between obese and overweight subjects, age, WHR, SBP, DBP measurements, serum 25(OH)D, PTH and lipid levels did not differ $(p>0.05)$. In overweight subjects, baseline FBG, insulin, and HOMA-IR levels were significantly lower than in obese subjects (91.8 \pm 5.7 vs. $96.5 \pm 7.6 ; p<0.001 ; 12.9$ vs. 16.4 , $p=0.001 ; 3.6$ vs. $4.2, p<0.001$; respectively).

In both groups, the effects of vitamin D supplementation on anthropometric and laboratory findings are shown in Table II. After supplementation, the laboratory parameters of overweight and obese subjects were as follows. Following vitamin $D_{3}$ supplementation in overweight and obese subjects, serum 25(OH)D increased from 6.1 to $34.7 \mathrm{ng} / \mathrm{ml}$ and 5.6 to $34.7 \mathrm{ng} / \mathrm{ml}$, respectively ( $p<0.001)$. In both groups, mean LDL-C level decreased ( $p=0.046, p=0.044$; respectively). In overweight subjects, TG level decreased after supplementation $(p<0.001)$, while no significant difference was observed in obese subjects $(p>0.05)$. In both subject groups mean FBG levels decreased and mean calcium levels increased $(p<0.001$; for both). After supplementation, mean phosphorus level decreased ( $p=0.011)$ in overweight subjects, while no difference was detected in obese subjects $(p>0.05)$. The relative changes of all parameters before and after supplementation compared between overweight and obese groups are shown in Table III. The effect of supplementation on percent change in all parameters is shown in Table II. Analysis between the groups shows that the percent change of HOMA-IR levels differed significantly between overweight and obese groups ( $p=0.035)$.

After supplementation, iPTH, insulin, and HOMA-IR levels decreased in both overweight and obese subjects $(p<0.001)$. Changes in all parameters from baseline to post-supplementation levels 
Table I. Baseline demographic, anthropometric and laboratory characteristics of all cases of overweight and obese patients

\begin{tabular}{|lcccc|}
\hline Variables & All patients $(n=122)$ & Overweight $(n=72)$ & Obese $(n=50)$ & $P$-value ${ }^{\#}$ \\
\hline Age $[$ years] & $43.1 \pm 10.4$ & $42.5 \pm 10.8$ & $43.9 \pm 10.1$ & 0.460 \\
\hline BMI $\left[\mathrm{kg} / \mathrm{m}^{2}\right]$ & $30.8 \pm 4.6$ & $27.5 \pm 1.2$ & $35.5 \pm 3.7$ & $<0.001^{*}$ \\
\hline WHR $[\mathrm{cm}]$ & $0.7 \pm 0.1$ & $0.7 \pm 0.1$ & $0.8 \pm 0.1$ & 0.078 \\
\hline SBP $[\mathrm{mm} \mathrm{Hg}]$ & $122.7 \pm 10.1$ & $122.3 \pm 10.8$ & $123.3 \pm 8.9$ & 0.576 \\
\hline DBP $[\mathrm{mm} \mathrm{Hg}]$ & $74.5 \pm 6.2$ & $73.6 \pm 6.2$ & $75.8 \pm 6.1$ & 0.058 \\
\hline TC $[\mathrm{mg} / \mathrm{dl}]$ & $215.0 \pm 44.9$ & $215.1 \pm 45.3$ & $214.9 \pm 45.0$ & 0.978 \\
\hline LDL-C $[\mathrm{mg} / \mathrm{dl}]$ & $135.2 \pm 38.1$ & $137.1 \pm 37.5$ & $132.4 \pm 39.2$ & 0.509 \\
\hline HDL-C $[\mathrm{mg} / \mathrm{dl}]$ & $53.7 \pm 12.4$ & $54.3 \pm 12.6$ & $52.9 \pm 12.2$ & 0.566 \\
\hline TG $[\mathrm{mg} / \mathrm{dll}]$ & $142.5(78.0-454.0)$ & $140.0(78.0-454.0)$ & $149.0(83.0-440.0)$ & 0.829 \\
\hline FBG $[\mathrm{mg} / \mathrm{dl}]$ & $93.7 \pm 6.9$ & $91.8 \pm 5.7$ & $96.5 \pm 7.6$ & $<0.001^{*}$ \\
\hline Calcium $[\mathrm{mg} / \mathrm{dl}]$ & $9.2 \pm 0.43$ & $9.1 \pm 0.5$ & $9.2 \pm 0.4$ & 0.336 \\
\hline Phosphorus $[\mathrm{mg} / \mathrm{dl}]$ & $3.4 \pm 0.5$ & $3.5 \pm 0.5$ & $3.3 \pm 0.5$ & $0.014^{*}$ \\
\hline $25(\mathrm{OH}) \mathrm{D}[\mathrm{ng} / \mathrm{ml}]$ & $6.0(2.9-22.0)$ & $6.1(2.9-15.8)$ & $5.6(3.0-22.0)$ & 0.901 \\
\hline iPTH $[\mathrm{pg} / \mathrm{ml}]$ & $75.5(31.6-174.7)$ & $75.5(38.3-169.0)$ & $75.3(31.6-174.7)$ & 0.886 \\
\hline Insulin $[\mu \mathrm{lU} / \mathrm{ml}]$ & $14.0(4.2-45.6)$ & $12.9(4.2-33.0)$ & $16.5(7.9-45.6)$ & $0.001^{*}$ \\
\hline HOMA-IR & $3.7(1.0-10.8)$ & $3.6(1.0-6.7)$ & $4.2(2.8-10.8)$ & $<0.001^{*}$ \\
\hline
\end{tabular}

\#Overweight vs. obese patients. ${ }^{*} p \leq 0.05$ indicates statistical significance. Numerical variables with normal distribution are expressed as mean \pm standard deviation. Numerical variables without normal distribution are shown as median (min.-max.). BMI - body mass index, WHR - waist-hip ratio, SBP - systolic blood pressure, DBP - diastolic blood pressure, TC - total cholesterol, LDL-C - low-density lipoprotein cholesterol, HDL-C - high-density lipoprotein cholesterol, TG - triglyceride, FBG - fasting blood glucose, 25(OH)D - 25-hydroxy vitamin D, IPTH - intact parathormone, HOMA-IR - homeostasis model assessment of insulin resistance.

Table II. Effects of vitamin D supplementation on anthropometric and laboratory parameters in overweight and obese subjects

\begin{tabular}{|c|c|c|c|c|c|c|}
\hline \multirow[t]{2}{*}{ Variable } & \multicolumn{3}{|c|}{ Overweight $(n=72)$} & \multicolumn{3}{|c|}{ Obese $(n=50)$} \\
\hline & Baseline & $\begin{array}{l}\text { After supple- } \\
\text { mentation }\end{array}$ & $P$-value & Baseline & $\begin{array}{l}\text { After supple- } \\
\text { mentation }\end{array}$ & $P$-value \\
\hline BMI $\left[\mathrm{kg} / \mathrm{m}^{2}\right]$ & $27.5 \pm 1.2$ & $27.5 \pm 1.3$ & 0.340 & $35.5 \pm 3.7$ & $35.5 \pm 3.8$ & 0.532 \\
\hline WHR $[\mathrm{cm}]$ & $0.8 \pm 0.1$ & $0.8 \pm 0.1$ & 0.057 & $0.8 \pm 0.1$ & $0.8 \pm 0.1$ & 0.058 \\
\hline $\mathrm{SBP}[\mathrm{mm} \mathrm{Hg}]$ & $122.3 \pm 10.8$ & $122.0 \pm 10.7$ & 0.681 & $123.3 \pm 8.9$ & $122.7 \pm 10.3$ & 0.277 \\
\hline $\mathrm{DBP}[\mathrm{mm} \mathrm{Hg}]$ & $73.6 \pm 6.2$ & $74.0 \pm 6.7$ & 0.131 & $75.8 \pm 6.1$ & $75.6 \pm 7.0$ & 0.389 \\
\hline $\mathrm{TC}[\mathrm{mg} / \mathrm{dl}]$ & $215.1 \pm 45.3$ & $204.3 \pm 40.7$ & 0.056 & $214.9 \pm 45.0$ & $207.4 \pm 41.7$ & 0.257 \\
\hline LDL-C [mg/dl] & $137.1 \pm 37.5$ & $128.4 \pm 36.0$ & $0.046^{*}$ & $132.4 \pm 39.2$ & $121.0 \pm 32.9$ & $0.044^{*}$ \\
\hline $\mathrm{HDL}-\mathrm{C}[\mathrm{mg} / \mathrm{dl}]$ & $54.3 \pm 12.6$ & $53.6 \pm 14.2$ & 0.631 & $53.0 \pm 12.2$ & $52.3 \pm 11.2$ & 0.550 \\
\hline TG [mg/dl] & $\begin{array}{c}140.0 \\
(78.0-454.0)\end{array}$ & $123.5(38.0-283.0)$ & $<0.001^{*}$ & $\begin{array}{c}149.0 \\
(83.0-440.0)\end{array}$ & $139.5(45.0-320.0)$ & 0.142 \\
\hline $\mathrm{FBG}[\mathrm{mg} / \mathrm{dl}]$ & $91.8 \pm 5.7$ & $87.1 \pm 6.5$ & $<0.001^{*}$ & $96.5 \pm 7.6$ & $92.2 \pm 5.5$ & $<0.001^{*}$ \\
\hline Calcium [mg/dl] & $9.1 \pm 0.5$ & $9.4 \pm 0.4$ & $<0.001^{*}$ & $9.2 \pm 0.4$ & $9.5 \pm 0.3$ & $<0.001^{*}$ \\
\hline Phosphorus [mg/dl] & $3.5 \pm 0.5$ & $3.4 \pm 0.4$ & $0.011^{*}$ & $3.3 \pm 0.5$ & $3.3 \pm 0.5$ & 0.933 \\
\hline $25(\mathrm{OH}) \mathrm{D}[\mathrm{ng} / \mathrm{ml}]$ & $6.1(2.9-15.8)$ & $34.7(26.4-70.3)$ & $<0.001^{*}$ & $5.6(3.0-22.0)$ & $34.7(26.8-56.8)$ & $<0.001^{*}$ \\
\hline iPTH [pg/ml] & $\begin{array}{c}75.6 \\
(38.3-169.0)\end{array}$ & $41.2(19.4-85.3)$ & $<0.001^{*}$ & $\begin{array}{c}75.3 \\
(31.6-174.7)\end{array}$ & $46.4(28.9-96.0)$ & $<0.001^{*}$ \\
\hline Insulin $[\mu \mid \mathrm{U} / \mathrm{ml}]$ & $12.9(4.2-33.0)$ & $3.7(2.0-5.8)$ & $<0.001^{*}$ & $16.5(8.0-45.6)$ & $8.6(4.1-37.2)$ & $<0.001^{*}$ \\
\hline HOMA-IR & $3.6(1.0-6.7)$ & $2.0(0.7-3.2)$ & $<0.001^{*}$ & $4.2(2.8-10.8)$ & $2.4(1.2-7.0)$ & $<0.001^{*}$ \\
\hline
\end{tabular}

Numerical variables with normal distribution are expressed as mean \pm standard deviation. Numerical variables without normal distribution are shown as median (min.-max.). ${ }^{*} p \leq 0.05$ indicates statistical significance. $\Delta p$ : Overweight baseline-after supplementation $v s$. obese $e_{\text {baseline-after supplementation. }}$ $B M I$ - body mass index, WHR - waist-hip ratio, SBP - systolic blood pressure, DBP - diastolic blood pressure, TC - total cholesterol, $L D L-C$ - low-density lipoprotein cholesterol, HDL-C - high-density lipoprotein cholesterol, TG - triglyceride, FBG - fasting blood glucose, 25(OH)D - 25-hydroxy vitamin D, iPTH - intact parathormone, HOMA-IR - homeostasis model assessment of insulin resistance. 
Narin Nasiroglu Imga, Alper Cagri Karci, Dilek Oztas, Dilek Berker, Serdar Guler

Table III. Relative changes in variables over the course of vitamin D supplementation

\begin{tabular}{|c|c|c|c|}
\hline Variable & $\begin{array}{l}\text { Overweight }(n=72) \\
\text { (\% change) }\end{array}$ & $\begin{array}{l}\text { Obese }(n=50) \\
(\% \text { change) }\end{array}$ & $\begin{array}{c}P \text {-value } \# \\
\text { Comparison of relative } \\
\text { change between groups }\end{array}$ \\
\hline BMI $\left[\mathrm{kg} / \mathrm{m}^{2}\right]$ & $-2.2 \pm 4.0$ & $-1.2 \pm 2.5$ & 0.263 \\
\hline WHR $[\mathrm{cm}]$ & $-0.5 \pm 1.8$ & $0.5 \pm 1.9$ & 0.139 \\
\hline $\mathrm{SBP}[\mathrm{mm} \mathrm{Hg}]$ & $-0.2 \pm 4.3$ & $-0.5 \pm 3.2$ & 0.675 \\
\hline $\mathrm{DBP}[\mathrm{mm} \mathrm{Hg}]$ & $0.2 \pm 2.7$ & $-0.4 \pm 2.6$ & 0.205 \\
\hline $\mathrm{TC}[\mathrm{mg} / \mathrm{dl}]$ & $-4.0 \pm 18.6$ & $-2.9 \pm 15.2$ & 0.823 \\
\hline LDL-C [mg/dl] & $-3.8 \pm 24.2$ & $-5.8 \pm 21.4$ & 0.753 \\
\hline $\mathrm{HDL}-\mathrm{C}[\mathrm{mg} / \mathrm{dl}]$ & $2.2 \pm 22.2$ & $0.8 \pm 16.5$ & 0.787 \\
\hline TG [mg/dl] & $-16.1 \pm 44.9$ & $-3.4 \pm 29.9$ & 0.226 \\
\hline $\mathrm{FBG}[\mathrm{mg} / \mathrm{dl}]$ & $-3.6 \pm 8.7$ & $-1.6 \pm 6.8$ & 0.254 \\
\hline Calcium [mg/dl] & $2.2 \pm 4.8$ & $2.4 \pm 6.0$ & 0.877 \\
\hline Phosphorus [mg/dl] & $-2.8 \pm 15.5$ & $3.0 \pm 15.1$ & 0.131 \\
\hline $25(\mathrm{OH}) \mathrm{D}[\mathrm{ng} / \mathrm{ml}]$ & $565.1 \pm 327.0$ & $552.8 \pm 327.9$ & 0.840 \\
\hline iPTH [pg/ml] & $-38.3 \pm 23.1$ & $-38.2 \pm 22.2$ & 0.986 \\
\hline Insulin $[\mu \mid \mathrm{U} / \mathrm{ml}]$ & $-54.8 \pm 18.3$ & $-47.2 \pm 19.0$ & 0.087 \\
\hline HOMA-IR & $-56.4 \pm 17.0$ & $-46.8 \pm 19.2$ & $0.035^{\star}$ \\
\hline
\end{tabular}

${ }^{*} p \leq 0.05$ indicates statistical significance. ${ }^{*}$ Comparison of relative change of variables between overweight and obese groups. BMI - body mass index, WHR - waist-hip ratio, SBP-systolic blood pressure, DBP-diastolic blood pressure, TC - total cholesterol, LDL-C - low-density lipoprotein cholesterol, HDL-C - high-density lipoprotein cholesterol, TG - triglyceride, FBG - fasting blood glucose, 25(OH)D - 25-hydroxy vitamin D, iPTH - intact parathormone, HOMA-IR - homeostasis model assessment of insulin resistance.

Table IV. Correlation of change in 25(OH)D and HOMA-IR levels with the change in anthropometric and laboratory parameters in overweight and obese subjects

\begin{tabular}{|c|c|c|c|c|c|c|c|c|}
\hline \multirow[t]{3}{*}{ Variables } & \multicolumn{4}{|c|}{ Overweight } & \multicolumn{4}{|c|}{ Obese } \\
\hline & \multicolumn{2}{|c|}{$\triangle 25(\mathrm{OH}) \mathrm{D}$} & \multicolumn{2}{|c|}{$\triangle \mathrm{HOMA-IR}$} & \multicolumn{2}{|c|}{$\triangle 25(\mathrm{OH}) \mathrm{D}$} & \multicolumn{2}{|c|}{$\triangle$ HOMA-IR } \\
\hline & $r$ & $p$ & $r$ & $p$ & $r$ & $p$ & $r$ & $p$ \\
\hline$\Delta 25(\mathrm{OH}) \mathrm{D}$ & - & - & -0.581 & $<0.001^{*}$ & - & - & -0.389 & $0.005^{*}$ \\
\hline$\triangle \mathrm{HOMA}-\mathrm{IR}$ & -0.581 & $<0.001^{*}$ & - & - & -0.389 & $0.005^{*}$ & - & - \\
\hline$\Delta \mathrm{BMI}$ & 0.078 & 0.516 & 0.096 & 0.424 & -0.214 & 0.106 & 0.078 & 0.591 \\
\hline$\Delta \mathrm{WHR}$ & -0.044 & 0.715 & 0.135 & 0.258 & -0.157 & 0.275 & 0.038 & 0.796 \\
\hline$\triangle S B P$ & 0.194 & 0.102 & -0.102 & 0.394 & 0.171 & 0.234 & -0.207 & 0.148 \\
\hline$\triangle \mathrm{DBP}$ & 0.087 & 0.467 & -0.178 & 0.136 & 0.140 & 0.333 & -0.052 & 0.722 \\
\hline$\Delta \mathrm{TC}$ & -0.001 & 0.990 & -0.034 & 0.778 & -0.067 & 0.644 & 0.012 & 0.936 \\
\hline$\Delta \mathrm{HDL}-\mathrm{C}$ & -0.039 & 0.742 & 0.022 & 0.855 & 0.233 & 0.103 & 0.024 & 0.867 \\
\hline$\Delta \mathrm{LDL}-\mathrm{C}$ & 0.036 & 0.763 & -0.063 & 0.597 & 0.027 & 0.854 & 0.047 & 0.748 \\
\hline$\Delta \mathrm{TG}$ & 0.159 & 0.183 & -0.157 & 0.187 & -0.098 & 0.499 & -0.100 & 0.490 \\
\hline$\triangle \mathrm{FBG}$ & -0.400 & $0.001^{*}$ & 0.180 & 0.129 & -0.362 & $0.010^{*}$ & 0.428 & $0.002^{*}$ \\
\hline$\Delta$ Calcium & -0.168 & 0.157 & 0.129 & 0.278 & -0.172 & 0.233 & 0.119 & 0.412 \\
\hline$\Delta$ Phosphorus & 0.065 & 0.588 & 0.001 & 0.991 & 0.170 & 0.239 & 0.176 & 0.221 \\
\hline$\triangle \mathrm{iPTH}$ & -0.024 & 0.843 & 0.034 & 0.777 & -0.291 & $0.040^{*}$ & 0.130 & 0.369 \\
\hline$\Delta$ Insulin & -0.552 & $<0.001^{*}$ & 0.296 & $0.012^{\star}$ & -0.584 & $<0.001^{*}$ & 0.330 & $0.019^{*}$ \\
\hline
\end{tabular}

${ }^{*} p \leq 0.05$ indicates statistical significance. $\Delta$ - baseline values - post-supplementation values. 25(OH)D - 25-hydroxy vitamin $D$, $B M I$ - body mass index, WHR - waist-hip ratio, SBP - systolic blood pressure, DBP - diastolic blood pressure, TC - total cholesterol, $H D L-C$ - high-density lipoprotein cholesterol, LDL-C - low-density lipoprotein cholesterol, TG - triglyceride, FBG - fasting blood glucose, IPTH - intact parathormone, HOMA-IR - homeostasis model assessment of insulin resistance. 
were compared $(\Delta \mathrm{p})$. Changes in TG and phosphorus levels were larger in overweight subjects $(p=0.048, p=0.035$; respectively). However, the change in HOMA-IR level was larger only in obese subjects $(p=0.004)$.

The correlation of changes in $25(\mathrm{OH}) \mathrm{D}$ and HOMA-IR levels with changes in anthropometric and laboratory findings after supplementation are shown in Table IV. In overweight subjects, change in $25(\mathrm{OH}) \mathrm{D}$ level was negatively correlated with change in HOMA-IR $(r=-0.581, p<0.001)$, FBG $(r=-0.400, p=0.001)$, and insulin $(r=-0.552$, $p<0.001)$ levels, while change in HOMA-IR level was positively correlated with change in insulin $(r=0.296 ; p=0.012)$ level. In obese subjects, change in $25(\mathrm{OH}) \mathrm{D}$ level was negatively correlated with change in HOMA-IR $(r=-0.389, p=0.005)$, FBG $(r=-0.362, p=0.01)$, iPTH $(r=-0.291, p=$ $0.040)$, and insulin $(r=-0.584 ; p<0.001)$ levels; change in HOMA-IR level was positively correlated with the change in FBG $(r=0.428 ; p=0.002)$ and insulin ( $r=0.330 ; p=0.019)$ levels. The correlation of change in $25(\mathrm{OH}) \mathrm{D}$ and HOMA-IR levels in overweight and obese subjects is shown in Figure 2. A negative adjusted correlation was detected between $\triangle 25(\mathrm{OH}) \mathrm{D}$ and $\triangle \mathrm{HOMA}-\mathrm{IR}$ levels in both overweight and obese subjects. Change in $25(\mathrm{OH}) \mathrm{D}$ level is a predictor of change in HOMA-IR level. We found that a $1 \mathrm{ng} / \mathrm{ml}$ increase in serum $25(\mathrm{OH}) \mathrm{D}$ level caused a 0.30-fold reduction in HOMA-IR level $(\beta \pm \mathrm{SE}=-0.30 \pm 0.10 ; p=0.002)$.

\section{Discussion}

Vitamin D deficiency and obesity are nutritional disorders that affect people worldwide. Several studies have demonstrated that supplementation of vitamin D has various effects on obesity, hypertension, DM, insulin sensitivity, lipid parameters, inflammatory markers and atherosclerosis risk. It is well recognized that the overweight population has a high prevalence of cardiovascular disease (CVD) risk factors such as hypertension, type 2 DM, hyperlipidemia, and atherosclerosis, similar to obese subjects. In rats and humans, adipose tissue has been found to be the main storage site of vitamin D [22, 23]. The mechanism is not clear, but it is suggested that obesity can cause vitamin $D$ deficiency through inadequate intake or as a result of deposition of vitamin D in the large adipose tissue mass [24]. Additionally, obese people spend less time outside and are exposed to less UV radiation [25].

Vitamin $D$ has effects on pancreatic islet cells through the vitamin D receptor (VDR), and polymorphisms of the VDR gene are related to insulin resistance and impaired insulin secretion [26]. Pancreatic $\beta$-cells have receptors for the active form of vitamin $D$, and the local production of

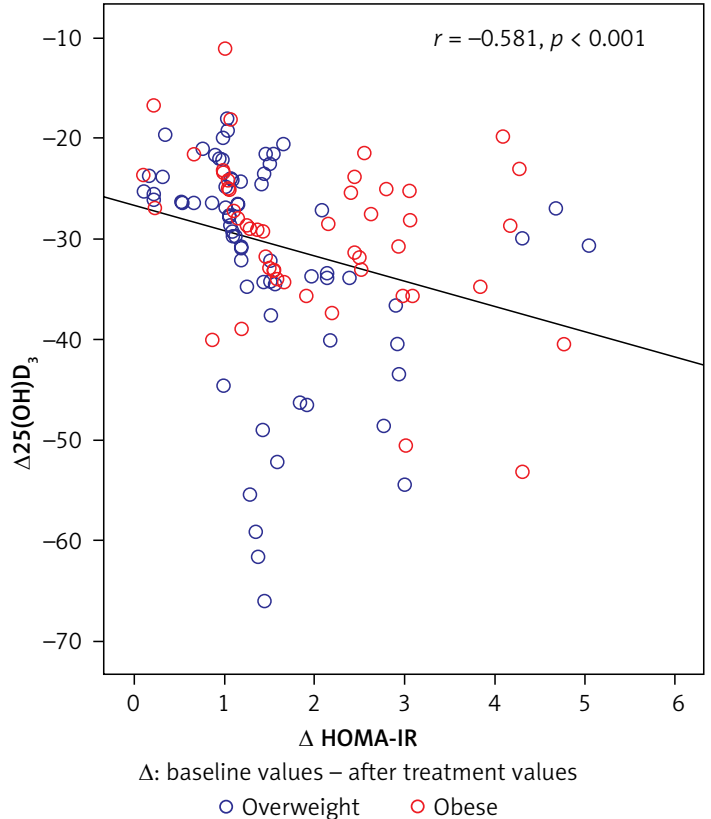

Figure 2. Correlation between changes (baseline vs. sixth month) in $25(\mathrm{OH}) \mathrm{D}$ levels and HOMA-IR

$1 \alpha, 25(\mathrm{OH})_{2} \mathrm{D}_{3}$ might be an essential mediator of islet function [27]. Some studies have demonstrated a negative correlation between serum vitamin $D$ levels and insulin resistance. A prospective study revealed an inverse relationship between baseline serum 25(OH)D and 10-year risk of hyperglycemia, metabolic syndrome, and insulin resistance [28]. Increasing 25(OH)D from 10 to $30 \mathrm{ng} / \mathrm{ml}$ can improve insulin sensitivity by $60 \%$ [29]. It is thought that vitamin D supplementation may be a cost-effective preventative and therapeutic agent for the management of insulin resistance and DM in obese individuals [30]. The present study demonstrated vitamin D-deficient overweight and obese subjects had higher HOMA-IR levels at baseline, whereas at the sixth month of supplementation it had declined. In addition, we observed a $1 \mathrm{ng} / \mathrm{ml}$ increase in serum $25(\mathrm{OH}) \mathrm{D}$ level that led to a 0.30 -fold reduction in HOMA-IR level. This result is important because it emphasizes that vitamin D deficiency should be corrected to prevent diseases caused by high insulin resistance. In our study, the obese group had higher insulin resistance than the overweight group; therefore, supplementation with vitamin D may be more beneficial for people with higher insulin resistance.

Vitamin D status is related to increased levels of endothelial dysfunction biomarkers, inflammatory markers and cardiometabolic risk factors in obese non-diabetic individuals [31]. The excess of macronutrients in the adipose tissues stimulates the release of inflammatory mediators and reduces production of adiponectin, predisposing to a pro-inflammatory state and oxidative stress. 
Management of obesity can help reduce the risks of CVD and inhibits release of inflammatory mediators [32]. However, a recent meta-analysis indicated that vitamin D supplementation had no effect on plasma leptin and adiponectin levels [33] Telomeres protect chromosomes from deterioration and fusion during mitosis. Higher vitamin D levels and longer telomere length have been associated with lower risk of several chronic diseases and all-cause mortality. A positive association was established between 25(OH)D levels and telomere length [34].

Some studies indicate that low 25(OH)D levels may lead to dyslipidemia. In the present study, vitamin D deficient women had higher LDL-C concentrations. After vitamin D supplementation, we observed LDL-C reduction in both overweight and obese subjects and TG reduction only in overweight subjects. Despite these reductions, no significant difference was found in TC and HDL-C levels. The mechanisms responsible for dyslipidemia in vitamin $D$ deficient individuals are not fully understood. A positive relationship between serum 25(OH)D level and apolipoprotein Al with $\mathrm{HDL}-\mathrm{C}$ levels is well known. Vitamin D can influence the formation of HDL-C particles [35]. Also, vitamin $\mathrm{D}$ status may affect the serum lipid levels by the effect of $1,25(\mathrm{OH})_{2} \mathrm{D}_{3}$, which leads to inhibition of murine bone marrow stromal cell differentiation and regulates adipogenesis; it also leads to increased lipogenesis and lipolysis [36]. Consistent with our results, an investigation of the effects of 25-hydroxyvitamin D on fasting lipid profile resulted in a negative correlation of $25(\mathrm{OH}) \mathrm{D}$ concentration with both total cholesterol and LDL-C [29].

The relationship between vitamin $D$ deficiency and CVD has been investigated in many studies. Active metabolites of vitamin D bind to the VDR, which regulates many genes in essential processes and has a role in pathways of CVD, including inflammation, thrombosis, and the renin-angiotensin system [37]. Women with vitamin D deficiency had increased CVD risk biomarkers such as homocysteine, high-sensitivity C-reactive protein (CRP), cystatin- $\mathrm{C}$, uric acid, and $\mathrm{HbA}_{1 \mathrm{c}}$ levels compared to those with sufficient vitamin $D$ levels [38]. Investigation of the possible role of vitamin D deficiency in statin-associated myalgia shows that low 25(OH)D levels are related to myalgia in patients on statin therapy [39]. In addition, peripheral artery disease patients had significantly higher serum concentrations of trans fatty acids and lower plasma levels of vitamin D [40]. Vitamin D induces prostacyclin in vascular smooth muscle cells; possibly, it is a vasoactive agent and may play a protective role in the development of atherosclerosis [41]. Gurses et al. reported that endo- thelial function is impaired in vitamin D deficient young premenopausal women; 6-month supplementation resulted in amelioration [42].

Non-alcoholic fatty liver disease (NAFLD) is the most common chronic liver disease worldwide, frequently co-existing with obesity, and has been recognized as an independent risk factor for CVD. Evidence from an increasing number of studies suggests that NAFLD may be a hepatic manifestation of metabolic syndrome [43]. Lifestyle changes and statin treatment have beneficial effects on NAFLD [44]. As a result of the correlation between hyperandrogenemia and NAFLD, bioavailable testosterone is independently associated with the fatty liver index in postmenopausal women [45]. Comparing the effect of orlistat versus metformin on body composition and insulin resistance in obese premenopausal women, it was found that orlistat and metformin produced similar improvement in insulin and glucose homeostasis [46]. Vitamin D deficiency is also associated with NAFLD and has even been correlated with the severity of the disease [47]. Vitamin D supplementation has a therapeutic role in vitamin $D$ deficient adults with NAFLD [48]. Also, low 25(OH)D levels are associated with advanced fibrosis and severe inflammation in autoimmune hepatitis. Vitamin D level was suggested as a biomarker that predicts response to therapy and histological features in autoimmune hepatitis [49]. In our study, both overweight and obese groups, after 6-month vitamin D supplementation, had a decline in iPTH concentrations and elevation in calcium levels. Studies showed that patients with secondary hyperparathyroidism have excess body weight and fat tissue [50]. It is suggested that PTH may cause insulin resistance by reducing glucose uptake by the liver, muscle, and adipose cells [51]. A recent study revealed that vitamin $D$ supplementation has no effect on CRP, interleukin-10, or tumor necrosis factor- $\alpha$ concentrations [52]

The 25(OH)D measurement before and after supplementation may not be a mirror of lifetime vitamin D status and progression of subclinical atherosclerosis over several years. In our opinion, these results may be a partial reflection of the situation of vitamin $D$ deficiency results. The results suggest that vitamin $D$ supplementation may be protective for possible dyslipidemia and insulin resistance, especially in patients above the normal weight.

Our study has several limitations. First, we analyzed baseline and 6-month measurements of parameters; frequent and longitudinal series of measurements may be more effective to evaluate the results. Second, this study was not a randomized placebo-controlled study. Third, we investigated the parameters in overweight and obese 
premenopausal women; in heterogeneous groups such as postmenopausal women and the male population, the results might have been different. Sun exposure and dietary daily vitamin D intake were not assessed, because this information was not available. In addition, we used the HOMA-IR index for the assessment of insulin resistance, but the lipid accumulation product and/or the triglyceride/glucose index can be applied as predictors of insulin resistance in clinical practice [53].

In conclusion, in healthy vitamin D deficient overweight and obese premenopausal women, 25(OH)D levels negatively correlated with HOMA-IR and LDL-C after vitamin D supplementation. These results may help highlight the importance of vitamin D supplementation to improve insulin secretion and insulin sensitivity, thereby indirectly influencing lipid metabolism and eventually prevention of atherosclerosis and cardiovascular mortality. Further studies are needed to confirm the effects of supplementation with vitamin D in healthy premenopausal overweight and obese women for insulin resistance and dyslipidemia.

\section{Conflict of interest}

The authors declare no conflict of interest.

\section{References}

1. DeLuca HF. Overview of general physiologic features and functions of vitamin D. Am J Clin Nutr 2004; 80: 1689S-96S.

2. Autier P, Gandini S. Vitamin D supplementation and total mortality: a meta-analysis of randomized controlled trials. Arch Intern Med 2007; 167: 1730-7.

3. Wang L, Manson JE, Song Y, Sesso HD. Systematic review: vitamin $D$ and calcium supplementation in prevention of cardiovascular events. Ann Intern Med 2010; 152: 315-23.

4. Garbossa SG, Folli F. Vitamin D, sub-inflammation and insulin resistance. A window on a potential role for the interaction between bone and glucose metabolism. Rev Endocr Metab Disord 2017; 18: 243-58.

5. Maki KC, Fulgoni III VL, Keast DR, Rains TM, Park KM, Rubin MR. Vitamin D intake and status are associated with lower prevalence of metabolic syndrome in US adults: National Health and Nutrition Examination Surveys 2003-2006. Metab Syndr Relat Disord 2012; 10: 363-72.

6. Cefalo CMA, Conte C, Sorice GP, et al. Effect of vitamin D supplementation on obesity-induced insulin resistance: a double-blind, randomized, placebo-controlled trial. Obesity (Silver Spring) 2018; 26: 651-7.

7. Song HR, Park CH. Low serum vitamin D level is associated with high risk of metabolic syndrome in post-menopausal women. J Endocrinol Invest 2013; 36: 791-6.

8. Leung PS. The potential protective action of vitamin $D$ in hepatic insulin resistance and pancreatic islet dysfunction in type 2 diabetes mellitus. Nutrients 2016; 8: 147.

9. Wamberg L, Pedersen SB, Rejnmark L, Richelsen B. Causes of vitamin D deficiency and effect of vitamin D supplementation on metabolic complications in obesity: a review. Curr Obes Rep 2015; 4: 429-40.

10. Mahmood SF, Idiculla J, Joshi R, Joshi S, Kulkarni S. Vitamin D supplementation in adults with vitamin D deficiency and its effect on metabolic syndrome - a randomized controlled study. Int J Vitam Nutr Res 2018 in press. doi: 10.1024/0300-9831/a000426.

11. El-Hajj Fuleihan G, Baddoura R, Habib RH, et al. Effect of vitamin $D$ replacement on indexes of insulin resistance in overweight elderly individuals: a randomized controlled trial. Am J Clin Nutr 2016; 104: 315-23.

12. Jamka M, Woźniewicz M, Jeszka J, Mardas M, Bogdański P, Stelmach-Mardas $M$. The effect of vitamin D supplementation on insulin and glucose metabolism in overweight and obese individuals: systematic review with meta-analysis. Sci Rep 2015; 5: 16142.

13. Mousa A, Naderpoor N, de Courten MP, et al. Vitamin D supplementation has no effect on insulin sensitivity or secretion in vitamin D-deficient, overweight or obese adults: a randomized placebo-controlled trial. Am J Clin Nutr 2017; 105: 1372-81.

14. Dutta D, Mondal SA, Choudhuri S, et al. Vitamin-D supplementation in prediabetes reduced progression to type 2 diabetes and was associated with decreased insulin resistance and systemic inflammation: an open label randomized prospective study from Eastern India. Diabetes Res Clin Pract 2014; 103: e18-23.

15. Karhapaa P, Pihlajamaki J, Porsti I, et al. Diverse associations of 25-hydroxyvitamin $D$ and 1,25-dihydroxy-vitamin D with dyslipidaemias. J Intern Med 2010; 268: 604-10.

16. Ponda MP, Huang X, Odeh MA, Breslow JL, Kaufman HW. Vitamin D may not improve lipid levels: a serial clinical laboratory data study. Circulation 2012; 126: 270-7.

17. Auwerx J, Bouillon R, Kesteloot H. Relation between 25-hydroxyvitamin D3, apolipoprotein A-I, and high density lipoprotein cholesterol. Arterioscler Thromb 1992; 12: 671-4.

18. Holick MF, Binkley NC, Bischoff-Ferrari HA, et al. Evaluation, treatment, and prevention of vitamin $D$ deficiency: an Endocrine Society clinical practice guideline. J Clin Endocrinol Metab 2011; 96: 1911-30.

19. Ogden CL, Carroll MD, Curtin LR, McDowell MA, Tabak CJ, Flegal KM. Prevalence of overweight and obesity in the United States, 1999-2004. JAMA 2006; 295: 1549-55.

20. Friedewald WT, Levy RI, Fredrickson DS. Estimation of the concentration of low-density lipoprotein cholesterol in plasma, without use of the preparative ultracentrifuge. Clin Chem 1972; 18: 499-502.

21. Matthews DR, Hosker JP, Rudenski AS, Naylor BA, Treacher DF, Turner RC. Homeostasis model assessment: insulin resistance and beta-cell function from fasting plasma glucose and insulin concentrations in man. Diabetologia 1985; 28: 412-9.

22. Rosenstreich SJ, Rich C, Volwiler W. Deposition in and release of vitamin D3 from body fat: evidence for a storage site in the rat. J Clin Invest 1971; 50: 679-87.

23. Mawer EB, Backhouse J, Holman CA, Lumb GA, Stanbury SW. The distribution and storage of vitamin $D$ and its metabolites in human tissues. Clin Sci 1972; 43: 413-31.

24. Wortsman J, Matsuoka LY, Chen TC, Lu Z, Holick MF. Decreased bioavailability of vitamin $D$ in obesity. Am J Clin Nutr 2000; 72: 690-3.

25. Compston JE, Vedi S, Ledger JE, Webb A, Gazet JC, Pilkington TR. Vitamin D status and bone histomorphometry in gross obesity. Am J Clin Nutr 1981; 34: 2359-63.

26. Chiu KC, Chuang LM, Yoon C. The vitamin D receptor polymorphism in the translation initiation codon is 
a risk factor for insulin resistance in glucose tolerant Caucasians. BMC Med Genet 2001; 2: 2.

27. Bland R, Markovic D, Hills CE, et al. Expression of 25-hydroxyvitamin D 3-1alpha-hydroxylase in pancreatic islets. J Steroid Biochem Mol Biol 2004; 89: 121-5.

28. Forouhi NG, Luan JA, Cooper A, Boucher BJ, Wareham NJ. Baseline serum 25-hydroxy vitamin $D$ is predictive of future glycemic status and insulin resistance. Diabetes 2008; 57: 2619-25.

29. Chiu KC, Chu A, Go VL, Saad MF. Hypovitaminosis D is associated with insulin resistance and beta cell dysfunction. Am J Clin Nutr 2004; 79: 820-5.

30. Leung PS. The potential protective action of vitamin D in hepatic insulin resistance and pancreatic islet dysfunction in type 2 diabetes mellitus. Nutrients 2016; 8: 147.

31. linčić B, Stokić E, Stošić Z, et al. Vitamin D status and circulating biomarkers of endothelial dysfunction and inflammation in non-diabetic obese individuals: a pilot study. Arch Med Sci 2017; 13: 53-60.

32. Ellulu MS, Patimah I, Khaza'ai H, Rahmat A, Abed Y. Obesity and inflammation: the linking mechanism and the complications. Arch Med Sci 2017; 13: 851-63.

33. Dinca M, Serban MC, Sahebkar A, et al. for Lipid Blood Pressure Meta-analysis Collaboration LBPMC Group. Does vitamin D supplementation alter plasma adipokines concentrations? A systematic review and metaanalysis of randomized controlled trials. Pharmacol Res 2016; 107: 360-71.

34. Mazidi M, Michos ED, Banach M. The association of telomere length and serum 25-hydroxyvitamin D levels in US adults: the National Health and Nutrition Examination Survey. Arch Med Sci 2017; 13: 61-5.

35. Kazlauskaite R, Powell LH, Mandapakala C, Cursio JF Avery EF, Calvin J. Vitamin D is associated with atheroprotective high-density lipoprotein profile in postmenopausal women. J Clin Lipidol 2010; 4: 113-9.

36. Zemel MB, Shi H, Greer B, Dirienzo D, Zemel PC. Regulation of adiposity by dietary calcium. FASEB J 2000; 14: 1132-8.

37. Norman PE, Powell JT. Vitamin D and cardiovascular disease. Circ Res 2014; 114: 379-93.

38. Faridi KF, Lupton JR, Martin SS, et al. Vitamin D deficiency and non-lipid biomarkers of cardiovascular risk. Arch Med Sci 2017; 13: 732-7.

39. Michalska-Kasiczak M, Sahebkar A, Mikhailidis DP, et al. Lipid and Blood Pressure Meta-analysis Collaboration (LBPMC) Group. Analysis of vitamin D levels in patients with and without statin-associated myalgia - a systematic review and meta-analysis of 7 studies with 2420 patients. Int J Cardiol 2015; 178: 111-6.

40. Mazidi M, Wong ND, Katsiki N, Mikhailidis DP, Banach $M$. Dietary patterns, plasma vitamins and Trans fatty acids are associated with peripheral artery disease. Lipids Health Dis 2017; 16: 254.

41. Wakasugi $M$, Noguchi $T$, Inoue $M$, et al. Vitamin D3 stimulates the production of prostacyclin by vascular smooth muscle cells. Prostaglandins 1991; 42: 127-36.

42. Gurses KM, Tokgozoglu L, Yalcin MU et al. Markers of subclinical atherosclerosis in premenopausal women with vitamin $D$ deficiency and effect of vitamin $D$ replacement. Atherosclerosis 2014; 237: 784-9.

43. Katsiki N, Perez-Martinez P, Anagnostis P, Mikhailidis DP, Karagiannis A. Is nonalcoholic fatty liver disease indeed the hepatic manifestation of metabolic syndrome? Curr Vasc Pharmacol 2018; 16: 219-27.

44. Athyros VG, Tziomalos K, Katsiki N, Doumas M, Karagiannis A, Mikhailidis DP. Cardiovascular risk across the histological spectrum and the clinical manifestations of non-alcoholic fatty liver disease: an update. World J Gastroenterol 2015; 21: 6820-34.

45. Klisic A, Kavaric N, Jovanovic M, Soldatovic I, Gligorovic-Barhanovic N, Kotur-Stevuljevic J. Bioavailable testosterone is independently associated with fatty liver index in postmenopausal women. Arch Med Sci 2017; 13: 1188-96.

46. Kujawska-Łuczak M, Musialik K, Szulińska M, et al. The effect of orlistat versus metformin on body composition and insulin resistance in obese premenopausal women: 3-month randomized prospective open-label study. Arch Med Sci 2017; 13: 725-31.

47. Cimini FA, Barchetta I, Carotti S, et al. Relationship between adipose tissue dysfunction, vitamin D deficiency and the pathogenesis of non-alcoholic fatty liver disease. World J Gastroenterol 2017; 23: 3407-17.

48. Sharifi N, Amani R. Vitamin D supplementation and non-alcoholic fatty liver disease: a critical and systematic review of clinical trials. Crit Rev Food Sci Nutr 2017; in press. doi: 10.1080/10408398.2017.1389693.

49. Efe C, Kav T, Aydin C, et al. Low serum vitamin D levels are associated with severe histological features and poor response to therapy in patients with autoimmune hepatitis. Dig Dis Sci 2014; 59: 3035-42.

50. Rejnmark L, Vestergaard P, Brot C, Mosekilde L. Parathyroid response to vitamin $D$ insufficiency: relations to bone, body composition and to lifestyle characteristics. Clin Endocrinol (Oxf) 2008; 69: 29-35.

51. Teegarden D, Donkin SS. Vitamin D: emerging new roles in insulin sensitivity. Nutr Res Rev 2009; 22: 82-92.

52. Mazidi $M$, Rezaie $P$, Vatanparast $H$. Impact of vitamin $D$ supplementation on C-reactive protein; a systematic review and meta-analysis of randomized controlled trials. BMC Nutrition 2018; 4: 1.

53. Mazidi M, Kengne AP, Katsiki N, Mikhailidis DP, Ba nach $M$. Lipid accumulation product and triglycerides/ glucose index are useful predictors of insulin resistance. J Diabetes Complications 2018; 32: 266-70. 